\title{
Study on the Bid Decision System of Renewable Energy for Buildings Based on FAHP and Intuitionistic Fuzzy Set TOPSIS Method
}

\author{
Yunna $\mathrm{Wu}$, Zhen Wang, and Shuai Geng
}

\begin{abstract}
In a renewable energy for buildings project, the owner needs the different contractors to complete it. In order to ensure the project's quality, we need a decision framework of renewable energy for buildings contractors selection. Currently, few research papers study contracting problems from the owners' perspectives, but from the contractors' about the renewable energy for buildings. Hence, This paper is first to summarize the influence factors of the renewable energy building contractors selection from the owners' perspectives, establish the basic conditions to screen the contractors and select the appropriate contractors from the aspects of business and technology. Then we use the Fuzzy AHP(Fuzzy Analytic Hierarchy Process) to determine the relative weights of the evaluation criteria and IFS-TOPSIS (the Intuitionistic Fuzzy Set Technique for Order Preference by Similarity to Ideal Solution) to rank the alternatives. Based on the aforementioned contents, the decision framework of renewable energy building contractors selection is established. The advantages of this decision framework have two: first, it can offer the contractors selection direction for the owners of renewable energy building; second, this decision framework can solve the information loss problem which will affect the reasonability and accuracy of the decision result. Finally, a China's case study proves this decision framework is effective.
\end{abstract}

Index Terms - Bid system, evaluation bid, renewable energy for buildings, intuitionistic fuzzy set (IFS), fuzzy analytic hierarchy process (FAHP), technique for order preference by similarity to ideal solution (TOPSIS).

\section{INTRODUCTION}

Evaluating bid has become the key activity to the bid system in the renewable energy building project. At present, few literatures study on whether to participate in project bidding to obtain the maximum self-interest from the contractor's perspective, rather than from the owner' perspective[1]-[3]. And the fact of matter is renewable energy building is blind to pursuit of technology and high economic costs or to focus only on the economic costs of renewable energy and ignoring technology. Therefore, the construction owner need urgently to screen the appropriate contractors is not only economical but also reasonable to consider the use of renewable energy technology.

Evaluating bids of renewable energy building is the

Manuscript received September 24, 2015; revised November 12, 2015

The authors are with North China Electric Power University, College of Economic and Management, No.2, Bei Nong Road, Hui Longguan Town, Chang Ping District, Beijing, China (e-mail: wu_yunna@163.com, 464345819@qq.com, gengshuai1208@163.com). important thing in the bidding activity. It's a multi-criteria decision making (MCDM) problem. In practical engineering, lowest bid evaluation method is widely used in China. But Too much attention to price is very easy to cause the not advanced technology, unscientific management, poor quality and delayed project. In recent years, comprehensive evaluation method is often utilized to make decision [1] [4]-[7]. A few researches focus on the general project, for instance, the fuzzy analytic hierarchy process (FAHP), the fuzzy set technique for order preference by similarity to ideal Solution(Fuzzy TOPSIS), Gray method. But some problems defects still exist in these methods.

There are some researches on green building [8]-[11], but seldom research has been found currently about the bid evaluation of renewable energy building, Ahn [12] reveals the potential impact of environmental cost criteria on the selection of a winning bid for a highway reconstruction project. Yan and Lai study the general building bidding from the two aspects of technology and business, But they does not emphasize the basic conditions of the contractors and without taking into account the use of renewable energy [4], [5]. It is necessary to establish a practical bid evaluation model for renewable energy building. This paper will study on the renewable energy building bidding from the basic condition, technology and business. With result that, the high cost and better renewable energy technology will be balanced.

In the previous evaluation methods, some qualitative criteria did not consider the personal preference, so the failure of bid evaluation was caused by subjective judgment deviation. The fuzzy set is used to consider human judgment, but only a single scale (membership). In other words, when peoples make a decision, there are two cases-only 'yes' or 'no'. However, this is not the case. The fact is people have three states when deciding things-'yes', 'no' and 'hesitation'. Thus, in the evaluation bid, some information is lost.

To sum up, this study is organized to solve the problems that the front involves. Section II summarizes the previous studies about this topic; Section III analyzes the bid evaluation criteria of the renewable energy building; Section IV proposes the implementation bid decision framework of the renewable energy building. Herein, the FAHP is used to determine the relative weights of the evaluation criteria and the the intuitionistic fuzzy set technique for order preference by similarity to ideal solution (IFS-TOPSIS) is used to rank the alternatives. Based on the aforementioned contents, Section $\mathrm{V}$ gives the real case to prove aforementioned framework. 


\section{LITERATURE REVIEW}

Since 1980s, competitive bidding methods have been introduced into the industry to supplement and gradually replace the previous assignment system for the procurement of construction projects. Lai presented the history of development of competitive bidding systems in China [5].The new method of bidding was adopted, originating from the extensive competition in the industrial market [13]. Ray realized contractor failure occurs resulting in emphasis on cost factor alone [14]. In general construction projects, many factors affecting the bidding decision making need to considered. For the renewable energy building, its technology takes extra consideration in bidding systems.

For construction owners, the most important decision is to find right contractor. This decision-making is based on the bid evaluation criteria that are uncertain, complex and vague. The analytic hierarchy process(AHP) method help to specify numerical weights representing the relative importance of each criterion as well as their associated selection criteria with respect to the goal [15]. Kamal and Subhi solved the problem of the project management using AHP method as a potential decision making method [16]. However, the traditional AHP can't reflect people's subjective consciousness. FAHP can simulate the subjective judgment by the fuzzy linguistic transformed into fuzzy number [7], [17]-[20]. Using fuzzy set theory, this approach computes the weighted values of factors that significantly affect the result of a project [1]. Chang introduced a extent of the fuzzy AHP [21]. This approach utilizes TFN to make pairwise comparisons of fuzzy AHP, and is applied to determine the weighs of the bid criteria. However, bidding criteria of renewable energy for buildings are absent from the owners' perspectives.

Many studies have developed models to estimate the bidding from the contractor's point of view. A model based on fuzzy sets theory is proposed and it takes into consideration both different criteria, objectives and evaluations of numerous decision-makers [22]. A risk based fuzzy TOPSIS framework is set up to evaluate and prioritize bidding opportunities and help contractors to assign their limited resources to near optimal selected projects [6]. A structured learning model toward improved bidding is developed for large construction firms [3]. Ferrando integrated AHP and ANP to analysis the public bidding improve of one section of a national road [23]. FAHP approach is used to select the suitable bridge construction method [24]. FAHP is applied to determine the relative weights of the evaluation criteria and Fuzzy TOPSIS is applied to rank the alternatives by Torfi [7]. These fuzzy evaluation methods that have only the definition of a membership cannot reflect human's the extent of hesitation.

\section{ANALYSIS OF THE BID EVALUATION CRITERIA OF THE RENEWABLE ENERGY BUILDING}

The aim of the construction owner is to find a suitable contractor in the wide range, through the process of bid decision system, the contractor with the highest integrated score will be selected. Above all, the owner attracts bidders to participate in the competition, by issuing tender notice, rules and conditions for trading. In the evaluating bid stage, experts help the owner to search for appropriate contractors. It is the key of successful evaluation bid how to set up the evaluation criteria and weights. It directly affects the quality of the bid's result. In this paper, the bid evaluation criteria are analyzed mainly by three aspects, namely, basic condition, business and technology (see Table I)

Basic condition criteria are usually used as the access qualifications of bidders. Only to meet the access conditions, the contractor can participate in the next step of the competitive bidding process. Any one of basic condition criteria are not satisfied, the contractor will lead to be rejected.

Among the technology criteria, renewable energy technical measure and solution criterion is to evaluate the reasonable utilization of renewable energy. They are the subjective criterion according to the experts' knowledge and experience and the bid experts can exercise discretion. So both the tenders and bidders followed this criterion and are easy to controversy.

As mentioned before, Contractors must conform the basic condition criteria in bidding threshold. And the block bid price is divided into the upper limit value to control the cost and the lower limit value to ensure the quality of the renewable energy building. The business criteria are designed as qualitative, such as the tender offer is divided into price analysis, the rationality of the sub project price and the price based on the rationality of the construction organization design. The scores of these criteria depend on experts' preference and subjective judgment. The technology criteria are performed independent scoring according the experts knowledge and experience.

\section{MethodOLOGY}

The methodology has been applied for evaluating bid of the renewable energy building (Fig. 1), Details as follows.

\section{A. Preparation Stage-Identification of the Evaluation Criteria and Review of the Basic Condition}

In this stage, the committee for evaluating bids organized by construction owners or an appointed agent. This committee is mainly responsible for bid evaluation or selecting contractors and composed of construction owners or agent and experts on technology and economics. Its membership is more than 5 persons and should be odd number. Experts should not be less than 2/3 of the total number of members. Experts provided from the experts' database of the State Council or province, autonomous regions are randomly selected from the construction owner.

Experts firstly establish the criteria and sub-criteria of the bid evaluation for the renewable energy. Then, according the bid documents and construction owners' demand, experts develop the review standards. All contractors will be evaluated by all committee members based on the above criteria. But the contractor must meet the examination of basic condition criteria, one of these is not met, the contractor is rejected. If the bidder is less than three, the bid is invalid and needs to rebid. Thus, basic condition criteria are used to review the contractor. When the contractor meets, there will 
be only two criteria left to evaluate, namely, business and technology.

\section{B. Identification Weights Stage}

The weights of criteria and sub-criteria need to be identified in this stage. There is time limit for the bidding work, so the method of setting weights is recommended for Easy operation and FAHP is simple and easy to operate is applied herein. FAHP method bases on the fuzzy consistent relation and fuzzy consistent matrix of fuzzy set theory.

The weights calculation steps of FAHP on the criteria of renewable energy building are as follows:

Step 1: Experts need to make comparison between criteria and sub-criteria. The judgment matrix of the evaluation is constructed. $B=\left(b_{i j}\right)_{n \times n}$ is the fuzzy complementary matrix, $b_{i}+b_{j}=1$

$$
b_{i j}=\left\{\begin{array}{cc}
0 & b_{j} \text { is more impor } \tan t \text { than } b_{i} \\
0.5 & b_{i} \text { and } b_{j} \text { are equally impor } \tan t \\
1 & b_{i} \text { is more impor } \tan t \text { than } b_{j}
\end{array}\right.
$$

Step 2: This judgment matrix is transformed into the fuzzy consistent matrix, namely

$$
\begin{gathered}
S_{i}=\sum_{k=1}^{n} b_{i k} \quad(i=1,2, \cdots, n) \\
S_{i j}=\frac{S_{i}-S_{j}}{2 m}+0.5
\end{gathered}
$$

So $S=\left(S_{i j}\right)_{n \times n}$ is the fuzzy consistent matrix.

TABLE I: CRITERIA AND SUB-CRITERIA OF THE EVALUATION BID OF THE RENEWABLE ENERGY BUILDING

\begin{tabular}{ll}
\hline \hline Attribute & criteria \\
\hline (A1)Basic Condition & The bidder qualification \\
& Tender deposit \\
& The valid period of the tender \\
& The project manager qualification \\
& Time limit \\
& Safety production \\
& The block bid price \\
\hline
\end{tabular}

(A2)Business
(a) Renewable energy performance
(b) The scale of the enterprise
(c) The financial situation
(d) The specific implementation and management of renewable energy technology

(e) The tender offer

(e1)Price analysis

(e2)The rationality of the sub project price

(e3)The price based on the rationality of (e4)the construction organization design

\section{$\begin{array}{ll}\text { (A3)Technology } & \text { (f) The general technical measures and solutions }\end{array}$}

(g) The renewable energy technical measures and solutions

\section{(g1)Water saving \\ (g2)Land saving \\ (g3)Material saving \\ (g4)Energy saving \\ (g5)Environmental protection}

(h) Construction organization plan

(i) Safe and civilized construction

Step 3: To determine the weight value.

$$
\omega_{i}(\alpha)=\alpha^{\frac{1}{n} \sum_{j=1}^{n} s_{i j}} / \sum_{k=1}^{n} \alpha^{\frac{1}{n} \sum_{j=1}^{n} S_{k j}}
$$

$\alpha$ is a coefficient. By increasing its value, the resolution of the scheme will be promoted.

\section{Bid Evaluation and Ranking Stage}

Intuitionistic Fuzzy Set (IFS) as the extended concept of fuzzy set has been used in the MCDM method. Using IFS, instinctive preference of the experts can be more accurately reflected. It's concept as follows.

Definition 1 [25]. Let $X=\left\{x_{1}, x_{2}, \cdots x_{n}\right\}$ be a universe of discourse. An intuitionistic fuzzy number $\tilde{A}$ in a finite set $X$ having the following form:

$$
\tilde{A}=\left\{<x, M_{\tilde{A}}(x), N_{\tilde{A}}(x)>\mid x \in X\right\}
$$

$M_{\tilde{A}}(x), N_{\tilde{A}}(x)$ are respectively defined as membership 
function and non-membership function.

$M_{\tilde{A}}(x), N_{\tilde{A}}(x) \in[0,1]$ and $0 \leq M_{\tilde{A}}(x)+N_{\tilde{A}}(x) \leq 1$.Then, the intuitionistic fuzzy index is $\pi_{\tilde{A}}(x)$ known as hesitancy degree which is belong to $\tilde{A}$ or not. $\pi_{\tilde{A}}(x)=1-M_{\tilde{A}}(x)-N_{\tilde{A}}(x)$ and $0 \leq \pi_{\tilde{A}}(x) \leq 1$.
Above all, the scoring standard is given by the bid committee. The experts perform the score according to degree of the experts' preference and no-preference for each criterion, and each criterion can be expressed as an intuitionistic fuzzy number by experts.

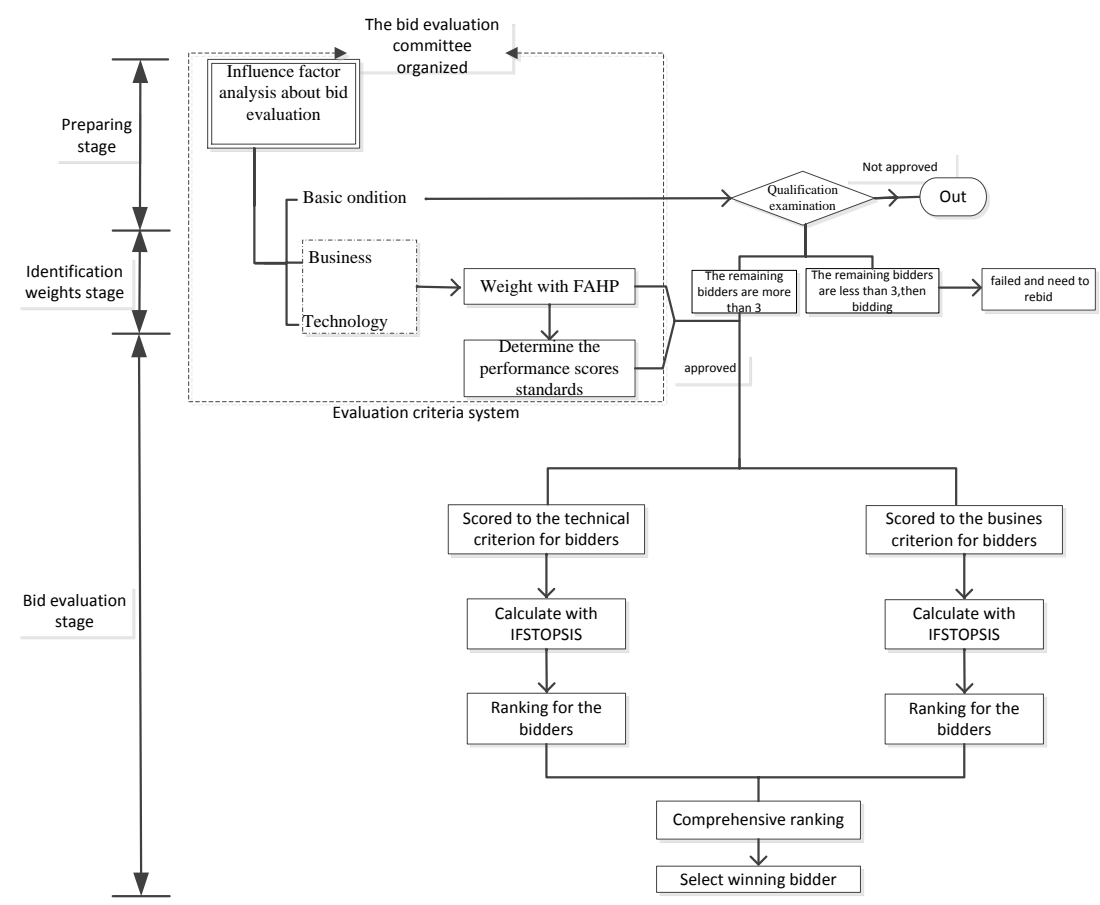

Fig. 1. Evaluation bid decision system of renewable energy building.

Next in importance is to evaluate bid and ranking by intuitionistic fuzzy set TOPSIS (IFS-TOPSIS). The Fuzzy TOPSIS method is widely used in multi-attribute decision making [26]-[31]. The decision matrix only represents the preference of the decision maker to accept or reject, but not to reflect the hesitancy degree of the decision makers. This is not consistent with the subjective consciousness of discrimination, So intuitionistic fuzzy sets is applied to the fuzzy TOPSIS in this paper to reflect the hesitancy degree.

For the fuzzy set $\tilde{A}$, the single degree of membership only contains a support $M_{\tilde{A}}(x)$ and opposition $N_{\tilde{A}}(x)$, but the intuitionistic fuzzy sets(IFS) extended fuzzy description of the phenomenon, namely support $M_{\tilde{A}}(x)$, oppose $N_{\tilde{A}}(x)$ and neutral $\pi_{\tilde{A}}(x)$.In the bid evaluation process, the subjective consciousness of experts can be relevantly reflected.

Definition 2. $\tilde{A}$ and $\tilde{B}$ are any two intuitionistic fuzzy sets on the domain of $\mathrm{X} . \lambda$ is any real number and $\lambda>0$. The operation relationship of intuitionistic fuzzy sets is as follows:

(1) $\tilde{A} \oplus \tilde{B}=\left\{<x, M_{\tilde{A}}(x)+M_{\tilde{B}}(x)-M_{\tilde{A}}(x) M_{\tilde{B}}(x)\right.$,

$$
\left.N_{\tilde{A}}(x) N_{\tilde{B}}(x)>\mid x \in X\right\}
$$

(2) $\tilde{A} \otimes \tilde{B}=\left\{<x, M_{\tilde{A}}(x) M_{\tilde{B}}(x)\right.$,

$$
\left.N_{\tilde{A}}(x)+N_{\tilde{B}}(x)-N_{\tilde{A}}(x) N_{\tilde{B}}(x)>\mid x \in X\right\}
$$

(3) $\lambda \tilde{A}=\left\{<x, 1-\left(1-M_{\tilde{A}}(x)\right)^{\lambda},\left(N_{\tilde{A}}(x)\right)^{\lambda}>\mid x \in X\right\}$

$$
\text { (4) } \tilde{A}^{\lambda}=\left\{<x,\left(M_{\tilde{A}}(x)\right)^{\lambda}, 1-\left(1-N_{\tilde{A}}(x)\right)^{\lambda}>\mid x \in X\right\}
$$

Definition 3. Let $A_{j}=<M_{j}, N_{j}>(j=1,2, \cdots, n)$ be an intuitionistic fuzzy set (IFS), the results obtained by the IFS weighting aggregation operator are still intuitionistic fuzzy sets and the formula of its aggregation is as follows:

$$
f_{\omega}^{A}\left(A_{1}, A_{2,} \cdots, A_{n}\right)=<1-\prod_{j=1}^{n}\left(1-M_{j}\right)^{\omega_{j}}, \prod_{j=1}^{n} N_{j}^{\omega_{j}}>
$$

In summary, the algorithm of IFS-TOPSIS for multi-attribute decision making is summarized as follows:

Step 1: The performance scores of criteria are given by the experts who are selected from experts' database. Based on the scoring standard, each expert assigns two scores between $0 \sim 1$ to represent the preference degree and dissatisfaction degree of each sub-criterion and criteria for contractor. These two scores are added to meet between 0 1.

Step 2: Calculating the performance scores of alternative. some sub-criteria are compensated and need to be aggregated. Such as, criterion of e is divided into sub-criterion of $e_{1}, e_{2}$ and $e_{3}$. These sub-criterion can be compensated and by Definition 3.

$\left.F=\left(<\mu_{i j}, v_{i j}\right\rangle\right)_{m \times n}$ is defined as the performance scores matrix of selecting contractors. This decision matrix obtained by experts scoring. the weight vector of intuitionistic fuzzy sets is denoted as $\omega=\left\{\omega_{1}, \omega_{2}, \cdots, \omega_{m}\right\}^{T}$,We obtained its value by FAHP is as stated before. So the weighted performance 
scores matrix is obtained as follows.

$$
\begin{aligned}
& \bar{F}=m \omega_{i} F_{i j}=<1-\left(1-\mu_{i j}\right)^{m \omega_{i}}, v_{i j}^{m \omega_{i}}>, \\
&(i=1,2, \cdots, m ; j=1,2, \cdots, n)
\end{aligned}
$$

Step 3: Determining the positive and negative ideal solutions of $\bar{F}$.

$$
\left\{\begin{array}{l}
A^{+}=<\mu_{i}^{+}, v_{i}^{+}>^{T}=\left\{\max _{1 \leq j \leq n} \bar{\mu}_{i j}, \min _{1 \leq j \leq n} \bar{v}_{i j}\right\} \\
A^{-}=<\mu_{i}^{-}, v_{i}^{-}>^{T}=\left\{\min _{1 \leq j \leq n} \bar{\mu}_{i j}, \max _{1 \leq j \leq n} \bar{v}_{i j}\right\}
\end{array} \quad(i=1,2, \cdots, m)\right.
$$

Step 4: Calculating the Euclidean distance of each bid document and the both ideal solution. Each bid document is denoted as $x_{j}(j=1,2, \cdots, n)$.

$$
\left\{\begin{array}{c}
D_{2}\left(x_{j}, A^{+}\right)=\left\{\frac{1}{2} \sum_{i=1}^{m}\left[\left(\bar{\mu}_{i j}-\mu_{i}^{+}\right)^{2}+\left(\bar{v}_{i j}-v_{i}^{+}\right)^{2}+\left(\bar{\pi}_{i j}-\pi_{i}^{+}\right)^{2}\right]\right\}^{1 / 2} \\
D_{2}\left(x_{j}, A^{-}\right)=\left\{\frac{1}{2} \sum_{i=1}^{m}\left[\left(\bar{\mu}_{i j}-\mu_{i}^{-}\right)^{2}+\left(\bar{v}_{i j}-v_{i}^{-}\right)^{2}+\left(\bar{\pi}_{i j}-\pi_{i}^{-}\right)^{2}\right]\right\}^{1 / 2} \\
(j=1,2, \cdots, n)
\end{array}\right.
$$

Among them:

$$
\bar{\pi}_{i j}=1-\bar{\mu}_{i j}-\bar{v}_{i j} ; \quad \pi_{i}^{+}=1-\mu_{i}^{+}-v_{i}^{+} ; \quad \pi_{i}^{-}=1-\mu_{i}^{-}-v_{i}^{-} .
$$

Step 5: Calculating the relative closeness degree of bid documents to the positive ideal solution. Relative closeness can be defined as $\varphi_{j}$

$$
\varphi_{j}=\frac{D_{2}\left(x_{j}, A^{-}\right)}{D_{2}\left(x_{j}, A^{+}\right)+D_{2}\left(x_{j}, A^{-}\right)}
$$

Step 6: According the order of the relative closeness degree, the ranking of alternatives and the winning bidder is determined.

\section{A CASE STUDY}

In yinchuan of ningxia, an owner wanted to construct six renewable energy residential buildings of 18 storey. The construction area is $95000 \mathrm{~m}^{2}$. renewable energy residential buildings used shear wall structure and the raft foundation. Renewable energy technologies are required. The project adopts open bidding. Five contractors participate in the bid for this renewable energy residential building. They are denoted as $t 1, t 2, t 3, t 4, t 5$ respectively. Five experts are selected in expert database randomly. They are composed of the committee for evaluating bids. Firstly, according to the literatures of the bid evaluation and experience of the experts,

\begin{tabular}{|c|c|c|c|c|c|c|c|}
\hline Attribute & $\begin{array}{c}\text { Absolute } \\
\text { weight }\end{array}$ & Criteria & $\begin{array}{c}\text { Relative } \\
\text { weight }\end{array}$ & $\begin{array}{c}\text { Absolute } \\
\text { weight }\end{array}$ & Sub-criteria & $\begin{array}{c}\text { Relative } \\
\text { weight }\end{array}$ & $\begin{array}{c}\text { Absolute } \\
\text { weight }\end{array}$ \\
\hline \multirow[t]{9}{*}{ A1 } & 0.240 & $\mathrm{a}$ & 0.086 & 0.021 & & & \\
\hline & & $\mathrm{b}$ & 0.086 & 0.021 & & & \\
\hline & & $\mathrm{c}$ & 0.216 & 0.052 & $\mathrm{c} 1$ & 0.216 & 0.011 \\
\hline & & & & & $\mathrm{c} 2$ & 0.466 & 0.024 \\
\hline & & & & & $\mathrm{c} 3$ & 0.318 & 0.016 \\
\hline & & $\mathrm{d}$ & 0.271 & 0.065 & & & \\
\hline & & $\mathrm{e}$ & 0.342 & 0.082 & e1 & 0.595 & 0.049 \\
\hline & & & & & $\mathrm{e} 2$ & 0.276 & 0.023 \\
\hline & & & & & e3 & 0.128 & 0.011 \\
\hline \multirow[t]{11}{*}{ A2 } & 0.760 & $\mathrm{f}$ & 0.159 & 0.120 & & & \\
\hline & & $\mathrm{g}$ & 0.376 & 0.286 & g1 & 0.083 & 0.024 \\
\hline & & & & & g2 & 0.083 & 0.024 \\
\hline & & & & & g3 & 0.209 & 0.060 \\
\hline & & & & & $\mathrm{g} 4$ & 0.416 & 0.119 \\
\hline & & & & & g5 & 0.209 & 0.060 \\
\hline & & $\mathrm{h}$ & 0.376 & 0.286 & h1 & 0.221 & 0.063 \\
\hline & & & & & h2 & 0.294 & 0.084 \\
\hline & & & & & h3 & 0.392 & 0.112 \\
\hline & & & & & h4 & 0.093 & 0.027 \\
\hline & & $\mathrm{i}$ & 0.089 & 0.068 & & & \\
\hline
\end{tabular}
9 criteria and 15 sub-criteria are decided by the committee of bid evaluation experts.

Among them, the condition criterion (A1) must be met. If A1 is not met, the contractor is rejected. It will be taken as abandoned tender.

TABLE II: THE RELATIVE WEIGHTS AND THE ABSOLUTE WEIGHTS OF CRITERIA AND SUB-CRITERIA

Bids are opened. Evaluated and selected under supervision of the administration office. Owing to detail error of forming the bid documents basic condition is not met, $T_{4}$ and $T_{5}$ are rejected. Based on "provisional regulations on the bid 
evaluation committee and the bid evaluation method", there are three remaining effective tenders and bids continue. Next, other contractors will be assessed.

Then Using FAHP, the weights of other criteria and sub-criteria are determined. The pairwise comparison matrix of $\mathrm{g}$ is constructed-are denoted by $\mathrm{Bg}$. The intuitionistic fuzzy consistent matrix is obtained by using (1), (2), and Definition 1 -are denoted by Sg. And the weights of g1, g2, g3, g4, g5 are calculated by (3).

$$
\begin{gathered}
B_{g}=\left(\begin{array}{ccccc}
0.5 & 0.5 & 0 & 0 & 0 \\
0.5 & 0.5 & 0 & 0 & 0 \\
1 & 1 & 0.5 & 0 & 0.5 \\
1 & 1 & 1 & 0.5 & 1 \\
1 & 1 & 0.5 & 0 & 0.5
\end{array}\right) \\
S_{g}=\left(\begin{array}{lllll}
0.50 & 0.50 & 0.30 & 0.15 & 0.30 \\
0.50 & 0.50 & 0.30 & 0.15 & 0.30 \\
0.70 & 0.70 & 0.50 & 0.35 & 0.50 \\
0.85 & 0.85 & 0.65 & 0.50 & 0.65 \\
0.70 & 0.70 & 0.50 & 0.35 & 0.50
\end{array}\right) \\
\omega_{g}=\left(\begin{array}{ll}
0.083,0.083,0.209,0.416,0.209
\end{array}\right)^{\prime}
\end{gathered}
$$

Similarly, other criteria and sub-criteria are calculated. The value calculated by (3) is relative weight. In order to reflect the important degree of the whole criteria system, the absolute weights need to be determined in Table II.

The experts divided the rating into five grades according to degree of the experts' preference for each criterion of contractors (see Table III).

According to scoring standard, Three bidders $(T 1, T 2, T 3)$ were scored by bid evaluation experts' committee respectively in Table IV.

\begin{tabular}{ll}
\hline TABLE III: SCORING STANDARD OF THE EXPERTS FOR EACH CRITERION \\
\hline \hline Degree of preference & Scoring standard \\
\hline Excellent & $(0.9$ or more $, 0-0.1,0-0.1)$ \\
Better & $(0.8-0.9,0-0.3,0-0.3)$ \\
Good & $(0.7-0.8,0-0.4,0-0.4)$, \\
General & $(0.6-0.7,0-0.4,0-0.4)$ \\
bad & $(0.6$ and following, 0.4 or more, 0.4 or more $)$ \\
\hline
\end{tabular}

TABLE V: The Weighted PeRformance Scores of THE Alternative BIDDERS

\begin{tabular}{cccc}
\hline \hline & $T_{1}$ & $T_{2}$ & $T_{3}$ \\
\hline (a) & $(0.107,0.867)$ & $(0.072,0.881)$ & $(0.133,0.831)$ \\
(b) & $(0.095,0.831)$ & $(0.082,0.905)$ & $(0.111,0.831)$ \\
(c) & $(0.277,0.654)$ & $(0.178,0.709)$ & $(0.264,0.665)$ \\
(d) & $(0.270,0.637)$ & $(0.237,0.637)$ & $(0.310,0.557)$ \\
(e) & $(0.294,0.555)$ & $(0.378,0.504)$ & $(0.275,0.599)$ \\
(f) & $(0.394,0.435)$ & $(0.353,0.559)$ & $(0.441,0.435)$ \\
(g) & $(0.784,0.122)$ & $(0.758,0.132)$ & $(0.805,0.132)$ \\
(h) & $(0.766,0.110)$ & $(0.781,0.119)$ & $(0.786,0.085)$ \\
(i) & $(0.320,0.543)$ & $(0.374,0.544)$ & $(0.339,0.520)$ \\
\hline \hline
\end{tabular}

By the value of Table $\mathrm{V}$ and using (6), the vector of positive and negative ideal solution of the weighted performance scores is as follows respectively.

Among them, criteria of $c 1, c 2, c 3$ are compensable and the relative weights of $c 1, c 2, c 3$ has already been calculated. Equation (4) are used to aggregate $c 1, c 2$, and $c 3$. From the Definition 3 , the performance scores of criteria $c$ can be aggregated. Similarly criteria of e, $g, h$ also can be aggregated. For reflecting the degree of the different importance of each criterion, Equation (5) is used and the weighted performance score of the alternative bidders is obtained in Table V.

TABLE IV: The PERFormance SCORES OF THE ALTERnATIVE BIDDERS

\begin{tabular}{cccc}
\hline \hline & $T_{1}$ & $T_{2}$ & $T_{3}$ \\
\hline (a) & $(0.84,0.10)$ & $(0.70,0.13)$ & $(0.90,0.05)$ \\
(b) & $(0.80,0.05)$ & $(0.75,0.20)$ & $(0.85,0.05)$ \\
(c1) & $(0.85,0.06)$ & $(0.80,0.15)$ & $(0.87,0.10)$ \\
(c2) & $(0.90,0.05)$ & $(0.70,0.10)$ & $(0.87,0.05)$ \\
(c3) & $(0.85,0.10)$ & $(0.80,0.10)$ & $(0.84,0.10)$ \\
(d) & $(0.80,0.10)$ & $(0.75,0.10)$ & $(0.85,0.05)$ \\
(e1) & $(0.75,0.10)$ & $(0.85,0.05)$ & $(0.70,0.20)$ \\
(e2) & $(0.75,0.10)$ & $(0.85,0.10)$ & $(0.75,0.05)$ \\
(e3) & $(0.80,0.05)$ & $(0.88,0.06)$ & $(0.80,0.10)$ \\
(f) & $(0.75,0.10)$ & $(0.70,0.20)$ & $(0.80,0.10)$ \\
(g1) & $(0.80,0.05)$ & $(0.76,0.10)$ & $(0.86,0.10)$ \\
(g2) & $(0.85,0.10)$ & $(0.80,0.05)$ & $(0.90,0.05)$ \\
(g3) & $(0.80,0.10)$ & $(0.85,0.10)$ & $(0.80,0.10)$ \\
(g4) & $(0.85,0.08)$ & $(0.80,0.10)$ & $(0.85,0.10)$ \\
(g5) & $(0.83,0.10)$ & $(0.80,0.10)$ & $(0.87,0.10)$ \\
(h1) & $(0.80,0.10)$ & $(0.85,0.05)$ & $(0.85,0.05)$ \\
(h2) & $(0.85,0.05)$ & $(0.90,0.05)$ & $(0.80,0.06)$ \\
(h3) & $(0.80,0.10)$ & $(0.75,0.15)$ & $(0.85,0.05)$ \\
(h4) & $(0.80,0.05)$ & $(0.76,0.12)$ & $(0.83,0.10)$ \\
\hline \hline & $(0.85,0.05)$ & $(0.90,0.05)$ & $(0.87,0.04)$ \\
\hline
\end{tabular}

$$
\begin{aligned}
A^{+}= & (<0.133,0.831>,<0.111,0.831>,<0.277,0.654>, \\
& <0.310,0.557>,<0.378,0.504>,<0.441,0.435>, \\
& <0.805,0.122>,<0.786,0.085>,<0.374,0.520>)^{\prime} \\
A^{-}= & (<0.072,0.881>,<0.082,0.905>,<0.198,0.709>, \\
& <0.237,0.637>,<0.275,0.599>,<0.353,0.559>, \\
& <0.758,0.132>,<0.766,0.119>,<0.320,0.544>)^{\prime}
\end{aligned}
$$

Equation (7) is used to calculate the Euclidean distance of $T_{1}, T_{2}, T_{3}$ and both ideal solution of them. The Euclidean distance of the technical criteria and the business criteria are respectively as follow:

$$
\begin{array}{cc}
D_{2}^{T}\left(T_{1}, A^{+}\right)=0.073 & D_{2}^{T}\left(T_{1}, A^{-}\right)=0.112 \\
D_{2}^{T}\left(T_{2}, A^{+}\right)=0.125 & D_{2}^{T}\left(T_{2}, A^{-}\right)=0.056 \\
D_{2}^{T}\left(T_{3}, A^{+}\right)=0.036 & D_{2}^{T}\left(T_{3}, A^{-}\right)=0.126 \\
D_{2}^{B}\left(T_{1}, A^{+}\right)=0.107 & D_{2}^{B}\left(T_{1}, A^{-}\right)=0.115 \\
D_{2}^{B}\left(T_{2}, A^{+}\right)=0.184 & D_{2}^{B}\left(T_{2}, A^{-}\right)=0.099 \\
D_{2}^{B}\left(T_{3}, A^{+}\right)=0.100 & D_{2}^{B}\left(T_{3}, A^{-}\right)=0.129
\end{array}
$$


The relative closeness degree of the technical index and the business index are obtained by using (8) respectively.

$$
\begin{array}{lll}
\varphi_{T 1}^{T}=0.604 & \varphi_{T 2}^{T}=0.309 & \varphi_{T 3}^{T}=0.778 \\
\varphi_{T 1}^{B}=0.516 & \varphi_{T 2}^{B}=0.349 & \varphi_{T 3}^{B}=0.565
\end{array}
$$

In summary, $\varphi_{T 1}=0.583, \varphi_{T 2}=0.319, \varphi_{T 3}=0.727$, Comprehensive evaluation result of bidders is $T_{3}>T_{1}>T_{2}$, The comprehensive evaluation of bidder of $\mathrm{T} 3$ is the highest and becomes the first winning candidate.

In order to facilitate analysis and verification of the result of the evaluating bid, The bid committee of these renewable energy building perform sensitivity analysis to reveal effect on ranking of the bidders by changing the absolute weights of criteria. Two absolute weights of criteria are exchanged, meanwhile, the left absolute weights of criteria hold constant. The results of sensitivity analysis are in Table VI.

\begin{tabular}{|c|c|c|c|c|c|c|c|c|c|}
\hline exchange & $\varphi_{T 1}$ & $\varphi_{T 2}$ & $\varphi_{T 3}$ & ranking & exchange & $\varphi_{T 1}$ & $\varphi_{T 2}$ & $\varphi_{T 3}$ & ranking \\
\hline$(\mathrm{a}, \mathrm{b})$ & 0.583 & 0.319 & 0.727 & $T_{3}>T_{1}>T_{2}$ & $(\mathrm{a}, \mathrm{c})$ & 0.576 & 0.314 & 0.739 & $T_{3}>T_{1}>T_{2}$ \\
\hline$(\mathrm{a}, \mathrm{d})$ & 0.591 & 0.311 & 0.742 & $T_{3}>T_{1}>T_{2}$ & $(\mathrm{a}, \mathrm{e})$ & 0.593 & 0.267 & 0.793 & $T_{3}>T_{1}>T_{2}$ \\
\hline$(a, f)$ & 0.449 & 0.416 & 0.664 & $T_{3}>T_{1}>T_{2}$ & $(\mathrm{a}, \mathrm{g})$ & 0.604 & 0.311 & 0.752 & $T_{3}>T_{1}>T_{2}$ \\
\hline$(\mathrm{a}, \mathrm{h})$ & 0.606 & 0.299 & 0.755 & $T_{3}>T_{1}>T_{2}$ & $(\mathrm{a}, \mathrm{i})$ & 0.621 & 0.209 & 0.822 & $T_{3}>T_{1}>T_{2}$ \\
\hline$(b, c)$ & 0.599 & 0.312 & 0.741 & $T_{3}>T_{1}>T_{2}$ & $(b, d)$ & 0.617 & 0.310 & 0.744 & $T_{3}>T_{1}>T_{2}$ \\
\hline$(\mathrm{b}, \mathrm{e})$ & 0.622 & 0.266 & 0.794 & $T_{3}>T_{1}>T_{2}$ & $(b, f)$ & 0.475 & 0.416 & 0.665 & $T_{3}>T_{1}>T_{2}$ \\
\hline$(b, g)$ & 0.607 & 0.317 & 0.744 & $T_{3}>T_{1}>T_{2}$ & $(b, h)$ & 0.609 & 0.305 & 0.747 & $T_{3}>T_{1}>T_{2}$ \\
\hline$(\mathrm{b}, \mathrm{i})$ & 0.645 & 0.208 & 0.824 & $T_{3}>T_{1}>T_{2}$ & $(\mathrm{c}, \mathrm{d})$ & 0.589 & 0.318 & 0.727 & $T_{3}>T_{1}>T_{2}$ \\
\hline$(\mathrm{c}, \mathrm{e})$ & 0.597 & 0.318 & .0727 & $T_{3}>T_{1}>T_{2}$ & $(\mathrm{c}, \mathrm{f})$ & 0.551 & 0.373 & 0.690 & $T_{3}>T_{1}>T_{2}$ \\
\hline$(\mathrm{c}, \mathrm{g})$ & 0.551 & 0.373 & 0.690 & $T_{3}>T_{1}>T_{2}$ & $(\mathrm{c}, \mathrm{h})$ & 0.594 & 0.307 & 0.738 & $T_{3}>T_{1}>T_{2}$ \\
\hline$(\mathrm{c}, \mathrm{i})$ & 0.599 & 0.294 & 0.748 & $T_{3}>T_{1}>T_{2}$ & $(d, e)$ & 0.595 & 0.287 & 0.756 & $T_{3}>T_{1}>T_{2}$ \\
\hline$(d, f)$ & 0.569 & 0.332 & 0.723 & $T_{3}>T_{1}>T_{2}$ & $(d, g)$ & 0.604 & 0.298 & 0.744 & $T_{3}>T_{1}>T_{2}$ \\
\hline$(\mathrm{d}, \mathrm{h})$ & 0.595 & 0.284 & 0.753 & $T_{3}>T_{1}>T_{2}$ & $(\mathrm{~d}, \mathrm{i})$ & 0.587 & 0.317 & 0.727 & $T_{3}>T_{1}>T_{2}$ \\
\hline$(e, f)$ & 0.575 & 0.332 & 0.712 & $T_{3}>T_{1}>T_{2}$ & $(e, g)$ & 0.575 & 0.332 & 0.712 & $T_{3}>T_{1}>T_{2}$ \\
\hline$(e, h)$ & 0.566 & 0.322 & 0.716 & $T_{3}>T_{1}>T_{2}$ & $(e, i)$ & 0.572 & 0.323 & 0.720 & $T_{3}>T_{1}>T_{2}$ \\
\hline$(f, g)$ & 0.553 & 0.321 & 0.721 & $T_{3}>T_{1}>T_{2}$ & $(\mathrm{f}, \mathrm{h})$ & 0.544 & 0.311 & 0.731 & $T_{3}>T_{1}>T_{2}$ \\
\hline$(\mathrm{f}, \mathrm{i})$ & 0.532 & 0.398 & 0.667 & $T_{3}>T_{1}>T_{2}$ & $(\mathrm{~g}, \mathrm{~h})$ & 0.583 & 0.319 & 0.727 & $T_{3}>T_{1}>T_{2}$ \\
\hline$(\mathrm{g}, \mathrm{i})$ & 0.575 & 0.337 & 0.718 & $T_{3}>T_{1}>T_{2}$ & $(\mathrm{~h}, \mathrm{i})$ & 0.568 & 0.324 & 0.727 & $T_{3}>T_{1}>T_{2}$ \\
\hline
\end{tabular}

TABLE VI: SENSITIVITY ANALYSIS

Judging from Table VI, the values of the relative closeness degree change. But the ranking of the contractors is no change. The $T_{3}$ is still the best choice. Thus, the sensitivity analysis has no impact on the evaluation result. These indicate the result of evaluation bid of the renewable energy building is reliable. According to the previous analysis, $T_{3}$ is the best choice as construction owner of the renewable energy building.

\section{CONCLUSION}

Bid evaluation play an important role in the bid decision system. In this study, conclusions can be drawn: Influence bid factors of the renewable energy building are analyzed from the owners' perspectives and its criteria are established. The biggest difference between the renewable energy building and other projects is renewable energy technology and ability is taken into consideration in the business criteria and the technology criteria, in the case of meeting the basic condition criteria. Based on the intuitionistic fuzzy set, FAHP is applied to determine the weights of criteria and sub-criteria and IFS-TOPSIS is applied to rank the alternatives.
As mentioned before, the bid decision framework is proposed. This framework can assist the owners to select the desired contractor and also assure the renewable energy building's quality and economy. Herein, application of the intuitionistic fuzzy set avoids lost information in the bid. It can reflect the degree of hesitation when the experts evaluate the bid, and can accord with the subjective consciousness.

\section{REFERENCE}

[1] J.-S. Chou and H. W. A.-D. Pham, "Bidding strategy to support decision-making by integrating fuzzy AHP and regression-based simulation," Automation in Construction, vol. 35, pp. 517-527, 2013.

[2] E. Cagno and A. Perego, "Muilti-criteria assessment of the probability of winning in the competitive bidding process," International Journal of Project Manangement, vol .19, pp. 313-324, 2001.

[3] H. Abdul-Rahman, C. Wang, and S. B. Malay, "Structured project learning model toward improved competitiveness in bidding for large construction firms," Journal of Civil Engineering and Management, vol. 18, no. 4, pp. 546-556, 2012.

[4] H.-Y. Yan, "The construction project bid evaluation based on gray relational model," Procedia Engineering, vol. 15, pp. 4553-4557, 2011.

[5] K. K. Lai, S. L. L., and S. Y. Wang, "A method used for evaluating bids in the chinese construction industry," International Journal of Project Management, vol. 22, no. 3, pp. 193-201, 2004. 
[6] M. R. Ravanshadnia and Hossein, "Semi-ideal bidding via a fuzzy TOPSIS project evaluation framework in risky environments," Journal of Civil Engineering and Management, vol. 19, pp. 106-115, 2013.

[7] R. Z. F. F. Torfi and S. Rezapour, "Fuzzy AHP to determine the relative weights of evaluation criteria and Fuzzy TOPSIS to rank the alternatives," Applied Soft Computing, vol. 10, no. 2, pp. 520-528, 2010.

[8] T. H. C. Ji, K. Jeong, and S.-B. Leigh, "A model for evaluating the environmental benefits of elementary school facilities," Journal of Environmental Management, vol. 132, pp. 220-229, 2014.

[9] L. M. S. K. H. Kok and M. R. Z. Abidin, "Evaluation of green roof as green technology for urban stormwater quantity controls," presented at 4th International Conference on Energy and Evironment, 2013.

[10] M. W. O. M. J. Kim and J. T. Kim, "A method for evaluating the performance of green buildings with a focus on user experience," Energy and Buildings, vol. 66, pp. 203-210, 2013.

[11] A. Verbruggen, "Performance evaluation of renewable energy support policies, applied on Flanders' tradable certificates system," Energy Policy, vol. 37, pp. 1385-1394, 2009.

[12] C. Ahn et al., "Consideration of the environmental cost in construction contracting for public works: $\mathrm{A}+\mathrm{C}$ and $\mathrm{A}+\mathrm{B}+\mathrm{C}$ bidding methods," Journal of Management in Engineering, vol. 29, no. 1, pp. 86-94, 2013.

[13] L. Fuzhou and N. Ting, Research on Biddding Methods in Chinese Construction Market, pp. 16-18, 2007.

[14] P. S. Ray et al., "Decision support system for bid evaluation," International Journal of Industrial Engineering-Theory Applications and Practice, vol. 12, no. 3, pp. 277-285, 2005.

[15] J. K. W. Wong and H. Li, "Application of the analytic hierarchy process (AHP) in multi-criteria analysis of the selection of intelligen building systems," Building and Environment, vol. 43, no. 1, pp. $108-125,2008$

[16] A. GhaffarianHoseini et al., "Sustainable energy performances of green buildings: A review of current theories, implementations and challenges," Renewable and Sustainable Energy Reviews, vol. 25, pp. $1-17,2013$.

[17] S.-J. Chen and S.-M. Chen, "Fuzzy risk analysis based on the ranking of generalized trapezoidal fuzzy numbers," Applied Intelligence, vol. 26, no. 1, pp. 1-11, 2006

[18] P. Jaskowski, S. Biruk, and R. Bucon, "Assessing contractor selection criteria weights with fuzzy AHP method application in group decision environment," Automation in Construction, vol. 19, no. 2, pp. 120-126, 2010.

[19] F. R. L. Junior, L. Osiro, and L. C. R. Carpinetti, "A comparison between Fuzzy AHP and Fuzzy TOPSIS methods to supplier selection," Applied Soft Computing, vol. 21, pp. 194-209, 2014.

[20] Y.-M. Wang, Y. Luo, and Z. Hua, "On the extent analysis method for fuzzy AHP and its applications," European Journal of Operational Research, vol. 186, no. 2, pp. 735-747, 2008

[21] D.-Y. Chang, "Applications of the extent analysis method on fuzzy AHP," European Journal of Operational Research, pp. 649-655, 1996.

[22] E. Plebankiewicz, "Contractor prequalification model using fuzzy sets," Journal of Civil Engineering and Management, vol. 15, no. 4, pp. 377-385, 2009

[23] J. P. Pastor-Ferrando et al., "An ANP- and AHP-based approach for weighting criteria in public works bidding," Journal of the Operational Research Society, vol. 61, no. 6, pp. 905-916, 2010.
[24] N.-F. Pan, "Fuzzy AHP approach for selecting the suitable bridge construction method," Automation in Construction, vol. 17, no. 8, pp. 958-965, 2008.

[25] T. A. K., Instuitionisic Fuzzy Sets and System, vol. 20, no. 1, pp. 87-96, 1986.

[26] F. Cavallaro, "Fuzzy TOPSIS approach for assessing thermal-energy storage in concentrated solar power (CSP) systems," Applied Energy, vol. 87, no. 2, pp. 496-503, 2010.

[27] H. Doukas, C. Karakosta, and J. Psarras, "Computing with words to assess the sustainability of renewable energy options," Expert Systems with Applications, vol. 37, no. 7, pp. 5491-5497, 2010.

[28] T. Kaya and C. Kahraman, "Multicriteria decision making in energy planning using a modified fuzzy TOPSIS methodology," Expert Systems with Applications, vol. 38, no. 6, pp. 6577-6585, 2011.

[29] A. Ouattara, "Economic and environmental strategies for process design," Computers \& Chemical Engineering, vol. 36, pp. 174-188, 2012.

[30] A. T. D. Perera, "A hybrid tool to combine multi-objective optimization and multi-criterion decision making in designing standalone hybrid energy systems," Applied Energy, vol. 107, pp. 412-425, 2013.

[31] E. Wang, "Benchmarking whole-building energy performance with multi-criteria technique for order preference by similarity to ideal solution using a selective objective-weighting approach." Applied Energy, vol. 146, pp. 92-103, 2015.

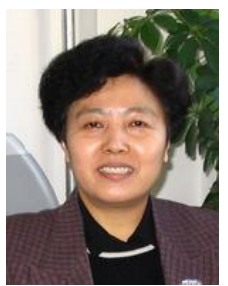

Yunna Wu was born in Jilin province, China in 1956 She received her master of engineering degree in civil engineering from North China Electric Power University in 1981. She is employed as a professor in North China Electric Power University. Her main research activities are: engineering and project management.

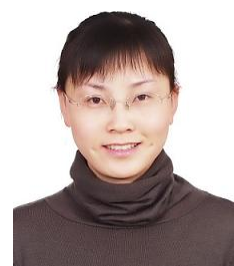

Zhen Wang was born in Ningxia, China, in 1979. She received her master of engineering degree in Beijing University of Civil Engineering and Architecture in 2008. She is employed as a lecturer in Ningxia University and currently working toward the Ph.D degree in engineering and project management, College of Economic and Management, North China Electric Power University. Her research mainly concerns on engineering and management

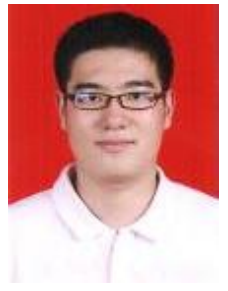

Shuai Geng was born in Jinan, China, in 1985. He received his master of engineering degree in Southwest Petroleum University in 2011. He is currently working toward the Ph.D. degree in engineering and project management, College of Economic and Management, North China Electric Power University. His research mainly concerns on electrical engineering and management 